\title{
Validation of the Spanish-language version of the Rapid Assessment for Adolescent Preventive Services among Colombian adolescents
}

\author{
Tatiana A. Suárez-Pinto, M.D. ${ }^{a}$, Argénida Blanco-Gómez, M.D. ${ }^{a}$, and Luis A. Díaz-Martínez, M.D. ${ }^{a}$
}

\begin{abstract}
Seventy percent of adolescent morbidity and mortality is related to six risky behaviors.

The Rapid Assessment for Adolescent Preventive Services is a screening questionnaire consisting of 21 questions but there is not a validated Spanish-language version.

The objective of this study was to validate the Spanish-language version of the Rapid Assessment for Adolescent Preventive Services in two Colombian cities: Bucaramanga and Medellín. The questionnaire was administered to 270 randomly selected adolescent students aged between 11 and 19 years old. Its internal consistency measured using Cronbach's alpha was 0.7207 . The factor analysis showed that two factors accounted for $84.5 \%$ of variance, but factor loading indicates that only one of these is valid in Colombia: substance use (tobacco, alcohol, narcotics, and psychoactive substances).

Key words: adolescent, result validity, Rapid Assessment for Adolescent Preventive Services, dangerous behavior.
\end{abstract}

http:/ /dx.doi.org/10.5546/aap.2016.eng.448

\section{INTRODUCTION}

Adolescence is a critical stage in the life cycle ${ }^{1}$ that ends in personality and identity formation. ${ }^{2}$ In the United States, up to $70 \%$ of adolescent morbidity and mortality is related to risky behaviors, including injuries, alcohol or psychoactive substance use, risky sexual behavior, tobacco use, unhealthy eating habits, and physical inactivity. ${ }^{3,4}$ An early identification of these behaviors allows to provide adequate support and develop prevention strategies. ${ }^{5}$ However, lack of time during office visits becomes a great hurdle in their identification. For

\footnotetext{
a. Department of Pediatrics, School of Medicine, School of Health, Universidad Industrial de Santander, Bucaramanga, Colombia.
}

E-mail address:

Tatiana A. Suárez-Pinto, M.D.: tatianasuarez1212@gmail.com

Funding: None.

Conflict of interest: None.

Received: 10-29-2015

Accepted: 02-26-2016 this reason, several screening instruments have been developed that aim at being time-effective. The Rapid Assessment for Adolescent Preventive Services (RAAPS) is one of these instruments.

The RAAPS was developed by the University of Michigan's School of Nursing. It consists of 21 questions related to six risky behaviors. ${ }^{6}$ Each risky behavior accounts for a domain in the theoretical construct which serves as the basis for this scale. The validity index of the Englishlanguage version is $0.825-1.0$, and its inter-rater kappa is $0.44-0.99$, granting the construct a highly relevant validity. ${ }^{\text {? }}$

There is a Spanish-language version of the RAAPS which has not been validated. This assessment may turn into a useful tool in primary care settings catering for Spanish-speaking adolescents.

The objective of this study is to validate the Spanish-language version of the RAAPS to screen for risky behaviors among Colombian adolescents.

\section{MATERIALS AND METHODS}

A study was conducted to validate the construct of the RAAPS Spanish-language version. High school students aged between 11 and 19 years old living in Bucaramanga and Medellín, with no disorders of perception that would prevent them from reading and writing with pen and paper, were included.

Permission to use the test was requested to its authors, who supplied the Spanish-language version provided that it was administered unchanged (Table 1). Participants referred comprehension problems with certain parts of the text, which were recorded and reported to authors after its validation. This study was approved by the Research Ethics Committee of Universidad Industrial de Santander (Resolution no. 30, December $5^{\text {th }}$, 2014).

Based on $80 \%$ reliability, it was expected that at least 10 subjects by item would be detected, in addition to a $10 \%$ potential loss due to parental refusal to participate. This meant that at least 230 adolescents had to be included. 
Participants were selected using a cluster random sampling process, which allowed identifying all high schools and the number of courses in each school in 2014; 18 groups from both cities were selected. Every student in each group was invited to participate. They were given an informed consent form to be duly completed by their parents or tutors and an assent form for themselves. ${ }^{8}$ Students who agreed to participate, and had both forms signed, completed the RAAPS anonymously, with no time constraints, supervision or help to answer any of the items.

Questionnaires that did not indicate the participant's age were excluded from the analysis. Although the RAAPS was designed for 11 to 19-year-old adolescents, we decided to include students who were 10 years old at the time of the survey because they were already in high school and would turn 11 during the school year. They were also considered to be exposed to the same risk factors.

The prevalence of affirmative answers to each of the 21 items was estimated together with a $95 \%$ confidence interval $(95 \% \mathrm{CI})$, and data were adjusted given the sampling process used, which may differ from the crude estimation of affirmative answers/population. ${ }^{9}$ For item 16, the proportion was estimated based on the total number of students who indicated to have had sexual intercourse.

Construct validity was analyzed with the Stata 12.1 software (StataCorp., College Station, USA, 2014) using Cronbach's alpha (overall and by item) and factor analysis to verify how theoretical

\section{TABLE 1. Spanish-language version of the Rapid Assessment for Adolescent Preventive Services}

1. In the past 12 months, have you tried to lose weight by obsessively exercising, taking diet pills or laxatives, making yourself vomit (throw up) after eating, or starving yourself?

2. Do you eat some fruits and vegetables every day?

3. Are you active after school or on weekends (walking, running, dancing, swimming, biking, playing sports) for at least 1 hour, on at least 3 or more days each week?

4. Do you always wear a seat belt when you are driving or riding in a car, truck, or van?

5. Do you always wear a helmet when you are biking, rollerblading, skateboarding, motorcycling, snowmobiling, skiing or snowboarding?

6. During the past month, have you been threatened, teased, or hurt by someone (on the internet, by text, or in person) or has anyone made you feel sad, unsafe, or afraid?

7. Has anyone ever abused you physically (hit, slapped, kicked), emotionally (threatened or made you feel afraid) or forced you to have sex or be involved in sexual activities when you didn't want to?

8. Have you ever carried a weapon (gun, knife, club, other) to protect yourself?

9. In the past 3 months, have you smoked cigarettes or any other form of tobacco (cigars, black and mild, hookah, other) or chewed/used smokeless tobacco?

10. In the past 12 months, have you driven a car drunk, high, or while texting or ridden in a car with a driver who was?

11. In the past 3 months, have you drunk more than a few sips of alcohol (beer, wine coolers, liquor, other)?

12. In the past 3 months, have you smoked marijuana, used other street drugs, steroids, or used inhalants ("huffed" household products)?

13. In the past 3 months, have you used someone else's prescription (from a doctor or other health provider) or any non-prescription (from a store) drugs to sleep, stay awake, concentrate, calm down, or get high?

14. Have you ever had any type of sex (vaginal, anal or oral sex)?

15. Have you ever been attracted to the same sex (girl to girl/guy to guy) or do you feel that you are gay, lesbian, or bisexual?

16. If you have had sex, do you always use a method to prevent sexually transmitted infections and pregnancy (condoms, female barriers, other)?

17. During the past month, did you often feel sad or down as though you had nothing to look forward to?

18. Do you have any serious problems or worries at home or at school?

19. In the past 12 months, have you seriously thought about killing yourself, tried to kill yourself, or have you purposely cut, burned or otherwise hurt yourself?

20. Do you have at least one adult in your life that you can talk to about any problems or worries?

21. When you are angry, do you do things that get you in trouble? 
domains behaved, at first directly and, if the model was inadequate, making rotations. Factors were considered likely if they had an eigenvalue $>1.0$ while items were considered part of a given factor if their factor loading was $\geq 0.5 \cdot{ }^{10,11}$

\section{RESULTS}

Out of 275 questionnaires administered between March and July 2015, five were excluded because participants had not indicated their age. Among those completed, $65.9 \%$ corresponded

TABLE 2. Prevalence of affirmative answers among 270 participating students

\begin{tabular}{lcc}
\hline Question & n (Crude prevalence) & Adjusted prevalence (95\% CI) \\
\hline Tries to lose weight inadequately (12 months) & $21(7.8 \%)$ & $8.6 \%(5.2-12.0)$ \\
Eats fruits and vegetables every day & $186(68.9 \%)$ & $74.8 \%(69.5-80.1)$ \\
Is physically active outside school & $186(68.9 \%)$ & $74.3 \%(69.0-79.5)$ \\
Always wears a seat belt & $159(58.9 \%)$ & $61.9 \%(56.1-67.8)$ \\
Always wears a helmet & $121(44.8 \%)$ & $47.4 \%(41.4-53.4)$ \\
Has been a victim of bullying (past month) & $44(16.3 \%)$ & $16.7 \%(12.2-21.1)$ \\
Has been abused physically, emotionally or sexually & $24(8.9 \%)$ & $8.9 \%(5.5-12.3)$ \\
Has carried a weapon & $23(8.5 \%)$ & $10.0 \%(6.4-13.7)$ \\
Has smoked tobacco (3 months) & $12(4.4 \%)$ & $4.8 \%(2.2-8.2)$ \\
Has driven a car drunk high, or while texting (12 months) & $13(4.8 \%)$ & $5.6 \%(2.8-8.3)$ \\
Has drunk more than a few sips of alcohol (3 months) & $57(21.1 \%)$ & $23.7 \%(18.6-28.8)$ \\
Has abused psychoactive substances or steroids (3 months) & $8(2.9 \%)$ & $2.4 \%(1.9-2.9)$ \\
Has abused medications (12 months) & $11(4.1 \%)$ & $3.3 \%(1.1-5.5)$ \\
Has had any type of sex & $34(12.6 \%)$ & $12.8 \%(8.8-16.9)$ \\
Is attracted to the same sex or feels that he/she is gay, lesbian, or bisexual & $12(4.4 \%)$ & $4.5 \%(2.0-7.0)$ \\
Always uses methods to prevent STI/pregnancy* & $24(70.5 \%)$ & $79.4 \%(62.1-91.3)$ \\
Has felt depressed (1 month) & $64(23.7 \%)$ & $27.1 \%(21.7-32.4)$ \\
Has had serious problems at home/school & $51(18.9 \%)$ & $20.0 \%(15.2-24.8)$ \\
Suicide/self-harm thoughts/attempts (12 months) & $23(8.5 \%)$ & $10.2 \%(6.5-13.8)$ \\
Has one adult that he/she can talk to about any worries & $201(74.4 \%)$ & $80.5 \%(75.7-85.3)$ \\
When angry, does things that get him/her in trouble & $75(27.7 \%)$ & $31.5 \%(25.9-37.1)$ \\
\hline
\end{tabular}

* Proportion estimated among the 34 students who indicated to have had sex.

TABLE 3. Cronbach's alpha analysis of the Rapid Assessment for Adolescent Preventive Services

\begin{tabular}{lccc}
\hline Ítem & Inter-item correlation & Item-test correlation & Item's alpha \\
\hline Tries to lose weight inadequately (12 months) & 0.3322 & 0.2345 & 0.7132 \\
Eats fruits and vegetables every day & 0.2606 & 0.2606 & 0.7137 \\
Is physically active outside school & 0.0828 & 0.0828 & 0.7322 \\
Always wears a seat belt & 0.2119 & 0.2119 & 0.7207 \\
Always wears a helmet & 0.2640 & 0.2640 & 0.7155 \\
Has been a victim of bullying (past month) & 0.3634 & 0.3634 & 0.7033 \\
Has been abused physically, emotionally or sexually & 0.2891 & 0.2891 & 0.7209 \\
Has carried a weapon & 0.3625 & 0.3625 & 0.7051 \\
Has smoked tobacco (3 months) & 0.3997 & 0.3997 & 0.7065 \\
Has driven a car drunk, high, or while texting (12 months) & 0.0410 & 0.0410 & 0.7255 \\
Has drunk more than a few sips of alcohol (3 months) & 0.3992 & 0.3992 & 0.6982 \\
Has abused psychoactive substances or steroids (3 months) & 0.3518 & 0.3518 & 0.7108 \\
Has abused medications (12 months) & 0.2839 & 0.2839 & 0.7130 \\
Has had any type of sex & 0.1990 & 0.1990 & 0.7171 \\
Is attracted to the same sex or feels that he/she is gay, lesbian, or bisexual & 0.3839 & 0.3839 & 0.7077 \\
Has felt depressed (1 month) & 0.4421 & 0.4421 & 0.6934 \\
Has had serious problems at home/school & 0.3565 & 0.3565 & 0.7036 \\
Suicide/self-harm thoughts/attempts (12 months) & 0.4433 & 0.4433 & 0.6992 \\
Has one adult that he/she can talk to about any worries & 0.3192 & 0.3192 & 0.7073 \\
When angry, does things that get him/her in trouble & 0.3089 & 0.3089 & 0.7089 \\
\hline
\end{tabular}


to Bucaramanga, $91.1 \%$ to students attending public schools, $56.1 \%$ were boys, and $81.1 \%$ lived in a middle socioeconomic level area. Students' mean age was 13.6 years old (standard deviation: 1.8 years old).

Table 2 shows the crude and adjusted prevalence of affirmative answers to the RAAPS items.

Cronbach's alpha was 0.7207 and ranged between 0.6982 and 0.7322 by item (Table 3). Factor analysis did not include item 16 because it was answered only by students who had had sexual intercourse. Two factors were thus observed: a factor with a 2.969 eigenvalue, which accounted for $61.44 \%$ of variance, made up of three items related to alcohol, psychoactive substance, and tobacco use. The second factor (with an eigenvalue of 1.116) accounted for $23.09 \%$ of variance, but there were no prevalent items. After making rotations, factor resolution did not improve (Table 4).

\section{DISCUSSION}

This is the first validation of the Spanishlanguage version of the RAAPS. Construct validity was acceptable, with no remarkable modifications after removing any of the items. ${ }^{10}$ However, only one factor made up of three items related to substance use was identified, ${ }^{11}$ and this indicates that, in Colombia, the RAAPS may only result useful to assess these risk factors.

Using factor analysis to assess constructs is based on verifying agreement or lack of agreement between the items exploring a risky behavior or domain and the answers given by a population. ${ }^{11}$ This means that, if the theoretical construct was true, questions specific to each risky behavior should be solved in the same direction and be part of the same factor. Thus, the North American theoretical risky behavior construct used to develop the RAAPS does not fit the Colombian setting.

Most of the participants attended public schools. In 2014, $82.9 \%$ of students in Bucaramanga and Medellín were enrolled in public schools, so the fact that the average number of students per course in public schools was twice the number in private schools does not allow to infer a bias in the cluster random sampling process.

The fact that the six expected risky behaviors did not appear in the factor analysis indicates

TABLE 4. Observed factor loading

\begin{tabular}{|c|c|c|c|}
\hline Aspect & Factor 1 & Factor 2 & Factor 3 \\
\hline Eigenvalue & 2.969 & 1.116 & 0.748 \\
\hline Explained variance & $61.44 \%$ & $23.09 \%$ & $15.49 \%$ \\
\hline \multicolumn{4}{|l|}{ Item } \\
\hline Tries to lose weight inadequately (12 months) & 0.279 & -0.168 & -0.092 \\
\hline Eats fruits and vegetables every day & -0.218 & 0.073 & 0.066 \\
\hline Is physically active outside school & -0.036 & 0.214 & -0.043 \\
\hline Always wears a seat belt & -0.156 & 0.084 & 0.356 \\
\hline Always wears a helmet & -0.213 & 0.055 & 0.358 \\
\hline Has been a victim of bullying (past month) & 0.463 & -0.329 & 0.263 \\
\hline Has been abused physically, emotionally or sexually & 0.320 & -0.314 & 0.279 \\
\hline Has carried a weapon & 0.412 & -0.020 & -0.170 \\
\hline Has smoked tobacco (3 months) & 0.620 & 0.218 & 0.106 \\
\hline Has driven a car drunk, high, or while texting (12 months) & 0.064 & 0.269 & -0.188 \\
\hline Has drunk more than a few sips of alcohol (3 months) & 0.498 & 0.063 & -0.253 \\
\hline Has abused psychoactive substances or steroids (3 months) & 0.652 & 0.469 & 0.158 \\
\hline Has abused medications (12 months) & 0.315 & -0.149 & -0.156 \\
\hline Has had any type of sex & 0.284 & 0.311 & -0.290 \\
\hline Is attracted to the same sex or feels that he/she is gay, lesbian, or bisexual & 0.480 & -0.128 & 0.071 \\
\hline Has felt depressed (1 month) & 0.455 & -0.396 & -0.047 \\
\hline Has had serious problems at home/school & 0.433 & -0.176 & 0.108 \\
\hline Suicide/self-harm thoughts/attempts (12 months) & 0.461 & -0.313 & -0.170 \\
\hline Has one adult that he/she can talk to about any worries & -0.280 & 0.216 & 0.049 \\
\hline When angry, does things that get him/her in trouble & 0.360 & -0.092 & -0.092 \\
\hline
\end{tabular}


that construct validity is not a property of the test itself, but of the population where it is administered..$^{12}$ The RAAPS was designed for North American students but, in this study, it was assessed in Colombian students, among whom different behaviors may prevail, especially considering that half of the participants were younger than 15 years old. It is also possible that participants were not even aware of the information necessary to answer regarding some behaviors, such as using a seat belt or the type of food they eat. However, the similar prevalence of affirmative answers regarding items related to alcohol, tobacco and illegal substance use, sexual intercourse initiation, ${ }^{14}$ and depression prevalence ${ }^{15}$ renders this explanation less likely.

Finally, the small number of questions per domain also hinders the possibility of achieving factor loading for at least three of them to be considered relevant for factor analysis.

Also, the effect on the lack of detection of other risky behavior groups cannot be estimated because the test has not been transculturally adapted; so it is necessary to study the RAAPS validity in depth and explore potential differences in behavior by outcome measure, e.g., age or sex groups, especially among adolescents older than 16 years old, in addition to assessing intra-subject reproducibility and sensitivity to change.

\section{CONCLUSION}

The RAAPS construct validity in the Colombian setting is acceptable but limited. It is very useful to detect alcohol, psychoactive substance, and tobacco use.

\section{REFERENCES}

1. OMS. Salud para los adolescentes del mundo: una segunda oportunidad en la segunda década. Ginebra: Servicio de Producción de Documentos de la OMS, 2014. [Accessed on: March 3, 2016]. Available at: http://apps. who.int/adolescent/second-decade/files / WHO_FWC MCA_14.05_spa.pdf.

2. UNICEF. Estado Mundial de la Infancia 2011: La adolescencia una época de oportunidades. Nueva York, 2011. [Accessed on: March 3, 2016]. Available at: https://
web.oas.org/childhood/ES / Lists / Recursos $\% 20 \% 20$ Bibliografia/Attachments/17/5.pdf.

3. Eaton DK, Kann L, Kinchen S, Shanklin S, et al. Youth risk behavior surveillance-United States, 2009. MMWRSurveill Summ 2010;59(5):1-142.

4. Shanklin S, Brener ND, Kann L, Griffin-BlakeS, etal. Youth risk behavior surveillance--selected steps communities, United States, 2007. MMWR Surveill Summ 2008;57(12): 1-27.

5. Bradford S, Rickwood D. Psychosocial assessments for young people: a systematic review examining acceptability, disclosure and engagement, and predictive utility. Adolesc Health Med Ther 2012;3:111-25.

6. Yi CH, Martyn K, Salerno J, Darling-Fischer CS. Development and clinical use of Rapid Assessment for Adolescent Preventive Services (RAAPS) questionnaire in school-based health centers. J Pediatr Health Care 2009; 23(1):2-9.

7. Salerno J, Marshall VD, Picken EB. Validity and reliability of the rapid assessment for adolescent preventive services adolescent health risk assessment. J Adolesc Health 2012;50(6):595-9.

8. República de Colombia. Ministerio de Salud. Resolución N. ${ }^{\circ} 008430$ de 1993. Bogotá, 4 de octubre de 1993. [Accessed on: March 3, 2016]. Available at: https://www.invima. gov.co/images/pdf/medicamentos/resoluciones/etica_ res_8430_1993.pdf.

9. Rabe-Hesketh S, Skrondal A. Multilevel and longitudinal modeling using Stata. Volume II: Categorical responses, counts, and survival. 3rd ed. College Station: Stata Press; 2012.

10. Oviedo HC, Campo-Arias A. Aproximación al uso del coeficiente alfa de Cronbach. Rev Colomb Psiquiatr 2005;34(4):572-80.

11. Campo-Arias A, Herazo E, Oviedo HC. Análisis de factores: fundamentos para la evaluación de instrumentos de medición en salud mental. Rev Colomb Psiquiatr 2012;41(3):659-71.

12. Kraemer HC. Population and sampling. In Evaluating medical test: objetive and quantitative guidelines. Newbury Park: Sage Publications; 1992.Págs.26-62.

13. República de Colombia. Ministerio de Protección Social, Dirección Nacional de Estupefacientes. Estudio Nacional de Consumo de Sustancias Psicoactivas en Colombia 2008. Bogotá: Ministerio de Protección Social; 2008.

14. Castillo M, Campo A, Silva Durán J, Meneses Moreno M, Navarrete Hernández P. Factores asociados con el inicio temprano de relaciones sexuales en estudiates adolescentes de un colegio de Bucaramanga, Colombia. Rev Colomb Psquiatr 2004;33(4):367-77.

15. Rodríguez Rodríguez DC, Dallos Bareño CM, González Rueda SJ, Sánchez Herrera ZM, et al. Asociación entre consumo de alcohol y síntomas depresivos en estudiantes e Bucaramanga, Colombia. Cad Saude Pública 2005; 21(5):109-18. 